\title{
Postpartum depression among women with pre-eclampsia and eclampsia in Tanzania; a call for integrative intervention
}

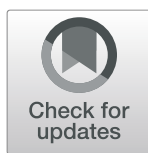

Barke Mbarak $^{1 *}$ D, Charles Kilewo', Saidi Kuganda 2,3 and Bruno F. Sunguya ${ }^{4}$

\begin{abstract}
Background: Postpartum depression (PPD) complicates maternal wellbeing, maternal-infant bonding, and cognitive function in children and woman's relationship with her partner. Clinical observations suggest a higher risk of postpartum depression among those women with pre-eclampsia and eclampsia compared to the general population. However, the evidence is inconsistent and not from settings similar to Tanzanian. This study aimed to determine the magnitude and risk factors for PPD among women diagnosed with pre-eclampsia or eclampsia at Muhimbili National Hospital (MNH), Tanzania.

Methods: This cross-sectional study was conducted among 390 women who had pre-eclampsia or eclampsia during pregnancy attending postnatal care clinic at MNH. PPD was assessed using Edinburg postnatal depression scoring scale (EPDS). Face to face interviews was conducted and data was analysed using descriptive and logistic regression analysis to address the two respective objectives.
\end{abstract}

Results: PPD was prevalent among $20.5 \%$ of women who had pre-eclampsia or eclampsia but varied with severity. Factors associated with PPD included young age ( $A O R=10.1395 \% \mathrm{Cl}$ 1.99-52.02), being a single mother ( $\mathrm{AOR}=$ $3.1895 \% \mathrm{Cl} 1.02-9.95)$, having a lower level of education ( $\mathrm{AOR}=3.8395 \% \mathrm{Cl} 1.45-10.16)$, having a perinatal death $(A O R=5.1495 \% \mathrm{Cl} 2.53-10.45)$, lack of family support (AOR $=7.0695 \% \mathrm{Cl} 1.25-39.90)$, and experience of stressful event during pregnancy (AOR $=15.1495 \% \mathrm{Cl}$ 2.38-96.19).

Conclusion: One in five women with pre-eclampsia or eclampsia had PPD and the magnitude increased with the severity of the disease condition. To address PPD, efforts should be done to screen and provide treatment to pregnant women presenting with pre-eclampsia or eclampsia, especially those with young age, low education level, single marital status, perinatal loss, lack of family support, and those reported to have a stressful event during pregnancy.

Keywords: Postpartum depression, Pre-eclampsia, Eclampsia

\section{Background}

Postpartum depression (PPD) is one of the common complications of childbirth affecting approximately $10-15 \%$ of women globally [1]. Such a burden is high in low and middle income countries [2-5]. Tanzania is no exception. Although evidence is minimal, unpublished hospital based study in Tanzania reported the prevalence of PPD to be $16.2 \%$.

Despite its devastating consequences to the woman, child, and family at large, PPD remains under-assessed

\footnotetext{
*Correspondence: b_abdulaziz@yahoo.co.uk

'Department of Obstetrics and Gynaecology, Muhimbili University of Health and Allied Sciences, 9 United Nations Road, 65001, Dar es Salaam, Tanzania Full list of author information is available at the end of the article
}

and often misinterpreted [6]. If untreated, it can impair maternal functioning. It is also associated with poor nutrition and health of the infant; interference with breastfeeding, maternal-infant bonding, care of the infant and other children; and can affect the woman's relationship with her partner $[7,8]$. Moreover, evidence suggests an association between PPD with abnormal child development, cognitive impairment, and psychopathology [9-11].

The aetiology for postpartum depression has complex pathophysiology and is likely to result from the interplay of genetic, neuroendocrine and psychosocial factors [12]. Other factors that predispose to the development of

(C) The Author(s). 2019 Open Access This article is distributed under the terms of the Creative Commons Attribution 4.0 International License (http://creativecommons.org/licenses/by/4.0/), which permits unrestricted use, distribution, and 
postpartum depressive illness include a history of mood disorders, and a family history of psychiatric disorders, negative life events, poor marital relationships, lack of social support, drug abuse, maternal perfectionism and antenatal depression or anxiety [13, 14]. The risk for PPD has also been found to increase in women with pregnancy and delivery complications including pregnancy-related hypertension [15]. Pre-eclamptic women most often experience mood disorders which may have long term effects in comparison to women with uncomplicated pregnancy [16]. The evidence further suggests an increase in the risk of PPD with the severity of pregnancy induced hypertension $[17,18]$.

A woman with pre-eclampsia or eclampsia is more likely to be exposed to different maternal and neonatal complications which may affect her psychological wellbeing. Studies in developed countries have reported increased rates of PPD in women with a history of preeclampsia or eclampsia. Anecdotal and isolated clinical observations also suggest an increase in PPD among such high-risk patients in Tanzania. However, the evidence is not systematically collected to inform policies on such observation. This has led to missed opportunities in early detection and prevention of such devastating condition. This study, therefore, sought to examine the magnitude of PPD and associated risk factors following pre-eclampsia or eclampsia among women attending postnatal care clinic at MNH. This study addressed the two research questions. First, what is the prevalence of Postpartum Depression among women who had pre-eclampsia or eclampsia attending postnatal care clinic at MNH? Second, what are the associated risk factors of Postpartum Depression among women who had pre-eclampsia or eclampsia attending postnatal care clinic at $\mathrm{MNH}$ ?

\section{Methodology}

\section{Study design, site}

This cross-sectional study was conducted in hospital settings of Muhimbili National Hospital (MNH) for six months from July 2016 to January 2017. MNH is the largest tertiary hospital in Tanzania, also serving as a referral hospital for high risk patients from other lower health facilities from Dar es Salaam and nearby regions. This is also designated as a training and teaching facility for Muhimbili University of Health and Allied Sciences (MUHAS). Care is provided by different cadres in the maternity unit under the supervision of specialist/consultant Obstetricians. MNH cares for on average about 1100 deliveries per month in a span of twelve months. Of these, 85 women are diagnosed with pre-eclampsia or eclampsia. Upon delivery, women diagnosed with preeclampsia or eclampsia are followed up in a postnatal clinic. This clinic serves an average of five women in a clinic day who had pre-eclampsia or eclampsia. There are four clinic days in a week, from Tuesdays to Fridays.

\section{Study population}

We included all postpartum women who were diagnosed with pre-eclampsia or eclampsia during pregnancy; delivered and attended postnatal clinic (PNC) at $\mathrm{MNH}$ for follow up. The final diagnosis of patients with the hypertensive disorder in pregnancy was made at $\mathrm{MNH}$ by the specialists/consultants Obstetricians. Moreover, such diagnosis is usually written on the discharge summary note given to the patients when discharged home. In this study, the diagnosis of pre-eclampsia or eclampsia was obtained from the discharge notes mentioned above.

Data collection was set from two weeks post-delivery and span to six weeks. Enrolment was restricted to 4 weeks only because our postnatal clinic at $\mathrm{MNH}$ mostly attends women who are between two and six weeks post-delivery. After six weeks, most women are referred to other specialty clinics such as cardiac clinics and those with no complications are encouraged to attend lower level health facilities for care.

\section{Sample size and sampling}

The sample size was calculated using the formula $\mathrm{N}=\mathrm{Z}^{2} \mathrm{P}$ $(1-\mathrm{P}) / \mathrm{D}^{2}$. Proportion $(\mathrm{P})$ assumed to be $50 \%$ since there were no published studies in Tanzania or East Africa on PPD in women who had pre-eclampsia or eclampsia. With assumptions of a $95 \%$ confidence interval, 5\% marginal error, the minimum sample size was estimated to be 384 . However, we collected a sample of 390 mothers who fulfilled the selection criteria.

Convenience sampling technique was used to select participants. All women who had pre-eclampsia or eclampsia, attending PNC clinic at $\mathrm{MNH}$ were included until the required sample size was reached. Recruitment of participants was done at the clinic through discharge summary note that was given to them on discharge from the hospital, which had the diagnosis of the patient when she was admitted.

\section{Measurements}

The outcome of interest was the Postpartum Depression measured using EPDS [19]. The 10-item EPDS explores events occurred in the immediate past 7 days. Each item

Table 1 Magnitude of PPD among participants ( $N=386)$

\begin{tabular}{llllll}
\hline Diagnosis & Total & \multicolumn{2}{l}{ EPDS Score } & $P$ value \\
\cline { 3 - 4 } & $N(\%)$ & $<13$ & $\geq 13$ & \\
\hline Mild pre-eclampsia & $153(100)$ & $137(89.5 \%)$ & $16(10.5 \%)$ & \\
Severe pre-eclampsia & $170(100)$ & $127(74.9 \%)$ & $43(25.3 \%)$ & \\
Eclampsia & $63(100)$ & $43(68.3 \%)$ & $20(31.7 \%)$ & $<0.001$ \\
Total & $386(100)$ & $307(79.5 \%)$ & $79(20.5 \%)$ & \\
\hline
\end{tabular}


Table 2 Characteristics of study participants $(\mathrm{N}=386)$ and their association with postpartum depression following Pre-eclampsia or Eclampsia

\begin{tabular}{|c|c|c|c|c|}
\hline \multirow[t]{2}{*}{ Variable } & \multirow[t]{2}{*}{ Total N (\%) } & \multicolumn{2}{|c|}{ Postpartum Depression } & \multirow[t]{2}{*}{$P$ value } \\
\hline & & Yes (\%) & No (\%) & \\
\hline \multicolumn{5}{|l|}{ Age (years) } \\
\hline \multicolumn{5}{|l|}{$(29.2 \pm 6.28)^{a}$} \\
\hline$<20$ & $30(7.8)$ & $13(43.3)$ & $17(56.6)$ & \multirow[t]{3}{*}{$<0.001^{*}$} \\
\hline $20-34$ & $269(69.7)$ & $58(21.6)$ & $211(78.4)$ & \\
\hline$\geq 35$ & $87(22.5)$ & $8(9.2)$ & 79 (90.8) & \\
\hline \multicolumn{5}{|l|}{ Marital status } \\
\hline Married/cohabiting & $322(83.4)$ & $43(13.4)$ & $279(86.6)$ & \multirow[t]{2}{*}{$<0.001^{*}$} \\
\hline Single/divorced/separated & $64(16.5)$ & $36(56.3)$ & $28(43.7)$ & \\
\hline \multicolumn{5}{|l|}{ Level of education } \\
\hline Lower level education & $262(67.9)$ & $65(24.8)$ & $197(75.2)$ & \multirow[t]{2}{*}{$0.002^{*}$} \\
\hline Higher level education & $124(32.1)$ & $14(11.3)$ & $110(88.7)$ & \\
\hline \multicolumn{5}{|l|}{ Occupation } \\
\hline Housewife/unemployed & $129(33.4)$ & $36(27.9)$ & $93(72.1)$ & \multirow[t]{3}{*}{$0.021^{*}$} \\
\hline Self employed & $198(51.3)$ & $36(18.2)$ & $162(81.1)$ & \\
\hline Employed & $59(15.3)$ & $7(11.9)$ & $52(88.2)$ & \\
\hline \multicolumn{5}{|l|}{ Parity } \\
\hline Primipara & $124(32.1)$ & $33(26.6)$ & $91(73.4)$ & \multirow[t]{2}{*}{$0.039^{*}$} \\
\hline Multipara & $262(67.9)$ & $46(17.6)$ & $216(82.4)$ & \\
\hline \multicolumn{5}{|l|}{ GA at delivery } \\
\hline Term & $214(55.4)$ & $37(17.3)$ & $177(82.7)$ & \multirow[t]{2}{*}{0.084} \\
\hline Preterm & $172(44.6)$ & $42(24.4)$ & $130(75.6)$ & \\
\hline \multicolumn{5}{|l|}{ Mode of delivery } \\
\hline Vaginal delivery & $208(53.9)$ & $39(18.8)$ & $169(81.2)$ & \multirow[t]{2}{*}{0.366} \\
\hline Caesarean section & $178(46.1)$ & $40(22.5)$ & $138(77.5)$ & \\
\hline \multicolumn{5}{|l|}{ Neonatal outcome } \\
\hline Livebirth & $286(74.1)$ & $44(15.4)$ & $242(84.6)$ & \multirow[t]{2}{*}{$<0.001^{*}$} \\
\hline Perinatal death & $100(25.9)$ & $35(35.0)$ & $65(65.0)$ & \\
\hline \multicolumn{5}{|l|}{ Neonatal admission } \\
\hline No admission & $228(59.0)$ & $50(21.9)$ & $178(78.1)$ & \multirow[t]{3}{*}{0.663} \\
\hline$<7$ days & $94(24.4)$ & $18(19.1)$ & $76(80.9)$ & \\
\hline$\geq 7$ days & $64(16.6)$ & $11(17.2)$ & $53(82.8)$ & \\
\hline \multicolumn{5}{|l|}{ Birthweight (grams) } \\
\hline$<2500$ & $189(49.0)$ & $46(24.3)$ & $143(75.7)$ & \multirow[t]{2}{*}{0.065} \\
\hline$\geq 2500$ & $197(51.0)$ & $33(16.8)$ & $164(83.2)$ & \\
\hline Family support & & & & \\
\hline Not satisfied & $49(12.7)$ & $36(73.5)$ & $13(26.5)$ & $0.001^{*}$ \\
\hline Satisfied & 337 (87.3) & $43(12.8)$ & $294(87.2)$ & \\
\hline Partner support & & & & \\
\hline Not supportive & $56(14.5)$ & 39 (69.6) & $17(30.4)$ & $<0.001^{*}$ \\
\hline Supportive & $330(85.5)$ & $40(12.1)$ & $290(94.5)$ & \\
\hline Partner relationship & & & & \\
\hline Very Good & $327(84.7)$ & $40(12.2)$ & $287(87.8)$ & $<0.001^{*}$ \\
\hline
\end{tabular}


Table 2 Characteristics of study participants $(\mathrm{N}=386)$ and their association with postpartum depression following Pre-eclampsia or Eclampsia (Continued)

\begin{tabular}{|c|c|c|c|c|}
\hline \multirow[t]{2}{*}{ Variable } & \multirow[t]{2}{*}{ Total N (\%) } & \multicolumn{2}{|c|}{ Postpartum Depression } & \multirow[t]{2}{*}{$P$ value } \\
\hline & & Yes (\%) & No (\%) & \\
\hline Good & $35(9.1)$ & $21(60.0)$ & $14(40.0)$ & \\
\hline Poor & $24(6.2)$ & $18(75.0)$ & $6(25.0)$ & \\
\hline \multicolumn{5}{|c|}{ Financial problems } \\
\hline Yes & $61(15.8)$ & 39 (63.9) & $22(36.1)$ & $<0.001^{*}$ \\
\hline No & $325(84.2)$ & $40(12.3)$ & $285(87.7)$ & \\
\hline \multicolumn{5}{|c|}{ Stressful event } \\
\hline Yes & $14(3.6)$ & $11(78.6)$ & $3(21.0)^{b}$ & $<0.001^{*}$ \\
\hline No & $372(96.4)$ & $68(18.3)$ & $304(81.7)$ & \\
\hline
\end{tabular}

Perinatal death - included women who had a stillborn baby or neonatal death GA gestation age

*significant association $(p<0.05)$

${ }^{a}$ mean age with standard deviation

${ }^{\mathrm{b}}$ Fischer's exact test used

has four choices scored from 0 to 3 from the first to last choice for item 1,2 and 4. The scores are reversed from 3 to 0 for questions $3,5,6,7,8,9$, and 10 . The sum ranges from 0 to 30. Mothers who scored 13 and above are likely to be suffering from a depressive illness of varying severity $[5,19,20]$. Mothers with such scores were counselled and referred for further care.

Independent variables included psycho-socio, demographic, and obstetric characteristics. They included maternal age, marital status, level of education, occupation, family support, partner support, and quality of relationship with partner, financial status, history of mental illness, stressful events during pregnancy, parity, and gestation age at delivery, mode of delivery, birth weight of baby, neonatal admission and perinatal death [21-25]. Details on the obstetric information were obtained from both the discharge note and the mother.

Data on family support was obtained by asking the participant on how she perceived the assistance she received from family, including emotional, informational or material assistance. Data on the quality of the relationship with a partner was obtained using a question with three responses as very good, good or poor. Having a financial problem, this was defined as a situation where a woman could not afford spending money on necessities such as food or medication.

The stressful event was defined as any adverse emotional event that had occurred during pregnancy. Participants were asked if there was any stressful event such as a death in the family, divorce, accident, job loss, or any event that participant defined as stressful. Responses were categorized as yes or no.

The questionnaire used was translated before data collection, into Swahili with the help of a language expert, and then translated back to English to ensure consistency of the meaning.
Data were collected from participants with preeclampsia and eclampsia. Mild Pre-eclampsia was defined as new onset of hypertension (systolic blood pressure $\geq 140 \mathrm{mmHg}$ or diastolic blood pressure $\geq 90$ $\mathrm{mmHg}$ ) and proteinuria $(\geq 0.3 \mathrm{~g}$. protein in $24 \mathrm{~h}$ urine specimen or $\geq 1+$ using a urinary dipstick) after 20 weeks of gestation in a previously normotensive woman.

Severe Pre-eclampsia was characterized by systolic blood pressure $\geq 160 \mathrm{mmHg}$, diastolic blood pressure $\geq$ $110 \mathrm{mmHg}$ at two occasions at least $4 \mathrm{~h}$ apart, with one or more complications such as thrombocytopenia, impaired liver function, renal insufficiency, pulmonary oedema, and new onset cerebral or visual disturbance. Eclampsia was defined as the presence of new-onset grandmal seizures in a woman with pre-eclampsia.

\section{Data collection}

The finalized tool was pre-tested by the first author on a total of ten women. The Cronbach's alpha for the EDPS was 0.89 showing adequate internal consistency. Only minor changes were done to improve the understanding of the other questionnaire items under the guidance of a psychiatrist, who is also a co-author.

A one-day training was conducted by the first author for the two research assistants who were also the nurse midwives working in maternity wards. They were trained on the purpose of the study, data collection techniques, and ethical issues pertinent to this study. Data were collected using face-to-face interviews after obtaining signed informed consent.

\section{Data analysis}

All questionnaires were checked by the investigator for completion. Data were then entered, cleaned and analysed using descriptive and regression methods through Statistical Package for Social Sciences (SPSS) version 
20.0. Four questionnaires were excluded due to missing data. Therefore, data of 386 participants were available for analysis. Results were expressed as frequencies and proportions for categorical variables and means and standard deviations for continuous variables. The prevalence of PPD was obtained as a percentage of women who scored $\geq 13$ on EPDS. Chi-square test was used to find the differences in the proportion of PPD across all variables for socio-demographic, psychosocial and obstetric factors. Crude odds ratio (OR) with $95 \%$ confidence interval was calculated for all study variables. Multivariate logistic regression was then run to compute

Table 3 Crude and adjusted odds ratio for the risk of PPD in women who had pre-eclampsia or eclampsia according to sociodemographic, obstetric and psychosocial variables $(N=79)$

\begin{tabular}{|c|c|c|c|c|}
\hline Variable & Depression N (\%) & OR $(95 \% \mathrm{Cl})$ & Adjusted OR $(95 \% \mathrm{Cl})$ & $P$ value \\
\hline \multicolumn{5}{|l|}{ Age (years) } \\
\hline$<20$ & $13(16.5)$ & $7.55(2.71-21.04)^{*}$ & 10.19 (1.99-52.02) & 0.005 \\
\hline $20-34$ & $58(73.4)$ & $2.71(1.24-5.94)^{*}$ & $5.7(1.93-17.06)$ & 0.002 \\
\hline$\geq 35$ & $8(10.1)$ & 1 & 1 & \\
\hline \multicolumn{5}{|l|}{ Marital status } \\
\hline Married/cohabiting & $43(54.4)$ & 1 & 1 & \\
\hline Single/divorced/separated & $36(45.6)$ & $8.34(4.63-15.04)^{*}$ & $3.18(1.02-9.95)$ & 0.047 \\
\hline \multicolumn{5}{|l|}{ Level of education } \\
\hline Lower level education & $65(82.3)$ & $2.59(1.39-4.83)^{*}$ & $3.83(1.45-10.19)$ & 0.007 \\
\hline Higher level education & $14(17.7)$ & 1 & 1 & \\
\hline \multicolumn{5}{|l|}{ Occupation } \\
\hline Housewife/unemployed & $36(45.6)$ & $2.88(1.19-6.92)^{*}$ & $0.78(0.23-2.67)$ & 0.690 \\
\hline Self employed & $36(45.6)$ & $1.65(0.69-3.93)$ & & \\
\hline Employed & $7(8.9)$ & 1 & & \\
\hline \multicolumn{5}{|l|}{ Parity } \\
\hline Primipara & $33(41.8)$ & $1.7(1.02-2.84)^{*}$ & $0.79(0.33-1.90)$ & 0.610 \\
\hline Multipara & $46(58.2)$ & 1 & 1 & \\
\hline \multicolumn{5}{|l|}{ Neonatal outcome } \\
\hline Livebirth & $44(55.7)$ & 1 & 1 & \\
\hline Perinatal death & $35(44.3)$ & $2.96(1.76-4.99)^{*}$ & $5.14(2.53-10.45)$ & $<0.001$ \\
\hline \multicolumn{5}{|l|}{ Family support } \\
\hline Not satisfied & $36(45.6)$ & $18.9(9.30-38.52)^{*}$ & $7.06(1.25-39.99)$ & 0.027 \\
\hline Satisfied & $43(54.4)$ & 1 & 1 & \\
\hline \multicolumn{5}{|l|}{ Partner support } \\
\hline Not supportive & $39(49.4)$ & $16.6(8.61-32.14)^{*}$ & $0.91(0.05-16.29)$ & 0.950 \\
\hline Supportive & $40(50.6)$ & 1 & 1 & \\
\hline \multicolumn{5}{|l|}{ Partner relationship } \\
\hline Very Good & $40(50.6)$ & 1 & 1 & \\
\hline Good & $21(22.8)$ & $10.8(5.07-22.85)$ & $0.71(0.04-12.26)$ & 0.810 \\
\hline Poor & $18(26.6)$ & $21.5(8.07-57.43)^{*}$ & $0.69(0.52-9.26)$ & 0.780 \\
\hline \multicolumn{5}{|l|}{ Financial problems } \\
\hline Yes & $39(49.4)$ & $12.6(6.8-23.45)^{*}$ & $2.53(0.79-8.03)$ & 0.120 \\
\hline No & $40(50.6)$ & 1 & 1 & \\
\hline \multicolumn{5}{|l|}{ Stressful event } \\
\hline Yes & $11(13.9)$ & $16.4(4.45-60.34)^{*}$ & 15.14 (2.38-96.19) & 0.004 \\
\hline No & $68(86.1)$ & 1 & 1 & \\
\hline
\end{tabular}

Perinatal death- included women who had a stillborn baby and neonatal death $N$ Number of participants, $O R$ odds ratio, $C l$ confidence interval

*significant association $(p<0.05)$ 
adjusted odds ratio (AOR) for variables with significant association to the dependent variable $(p<0.05)$ to determine the independent risk factors for PPD.

\section{Ethical considerations}

The study was approved by the Research and Ethics Committee of the Muhimbili University of Health and Allied Sciences and permission to conduct the study was obtained from the executive director of MNH. Participation was voluntary and signed informed consent was obtained before data collection. Confidentiality was maintained throughout by ensuring that no names were used that can identify the participant. Participants that were found to be at risk of PPD and those who had suicidal thoughts were counselled and referred to a psychiatrist for further evaluation and treatment.

\section{Results}

\section{The magnitude of postpartum depression}

Seventy-nine out of 386 participants had an EPDS score of 13 and above. This category was considered as having PPD giving a prevalence of $20.5 \%$ (Table 1 ). The mean score on the EPDS was $7.82 \pm 5.09$, with scores ranging from 0 to 25 . The magnitude of PPD was higher in eclampsia, and severe pre-eclampsia compared to mild pre-eclampsia $(p<0.001)$.

\section{Characteristics of study participants}

Majority of participants were between 20 and 34 years of age. Most of them were married or cohabiting, and about half of them were self-employed. Age, marital status and level of education showed significant association with PPD. Furthermore, all psychosocial variables showed significant association with PPD as well as some of the obstetric variables including parity and neonatal outcome (Table 2). None of the participants had prepregnancy history of depressive illness or any other psychological disorder.

\section{Factors associated with PPD}

Table 3 shows the findings of logistic regression analyses of factors associated with PPD among women who had pre-eclampsia or eclampsia. Young, single women with lower education level and those who had perinatal death were more likely to have PPD. Moreover, those who lacked family support, and who reported having experienced stressful event during pregnancy had higher chances of having PPD as compared to those who had family support and did not experience any stressful event.

\section{Discussion}

The magnitude of PPD among women with preeclampsia and eclampsia was found to be $20.5 \%$ increasing with the severity of hypertension in pregnancy. The associated factors in our setting include age, marital status, level of education, stressful events during pregnancy, family and partner support.

The magnitude of PPD found in this study is slightly higher compared to the general population in the same region. This suggests an additional effect that may be attributed by psychopathological complications associated with pre-eclampsia and eclampsia. Studies conducted in different contexts reported an even higher magnitude of PPD $[17,18]$. Although such a difference might be attributed to the contextual differences between Tanzania, Tehran, and the Netherlands, a different tool or cut-off point was also used. We used a more standardised questionnaire and recommended cut-off point for this condition [19].

Younger women diagnosed with pre-eclampsia or eclampsia were more likely to suffer from PPD compared to their older counterparts. Similar findings were also found in Canada, US [26-28]. However, the evidence is inconsistent on this regard in different settings such as Qatar, Brazil, and Cameroon [3, 21, 29]. Young maternal age has been associated with both increased risk of pre-eclampsia as well as PPD [30].

Single mothers were found to be at higher risk of getting PPD as compared to married mothers in our study. Single mothers may succumb to a number of psychosocial disadvantages. This may lead to a stressful situation, alter psychosocial stability, and therefore increased the risk of PPD. This finding is similar with evidence from Nigeria, Ghana, and India [31-33], but not to the body of evidence generated in US and Cameroon with regards to marital status [3, 27].

Similar to a number of studies [21, 28, 33, 34], we found a low level of education as a risk factor of PPD. Alternative or inconsistent findings were also reported elsewhere [3, 31, 35]. Low level of education is also associated with a number of social and economic disadvantages. Lack of awareness of some risky or danger signs including hypertension in pregnancy itself, self-care, among others may increase the risk of PPD. Moreover, the causal pathway for PPD is still unclear but the risk factors are known, and women with higher education level tend to be keen in following health advice given to keep themselves from possible risk factors.

Perinatal loss or any other loss for that matter is a risk for depression and other anxiety disorders [36]. In the context of hypertension in pregnancy, additional psychological trauma may further escalate the symptoms and lead to PPD. Our study found an association between such loss and PPD similar to studies in the Netherlands [18], Malaysia, and Bangladesh [37, 38]. Our study found associations between stressful events during pregnancy and PPD similar to other contexts [21, 39-41]. In the same pathway, even in the general population, having a 
stressful event is a trigger to depression. In addition to the trauma brought by pre-eclampsia or eclampsia and stress during pregnancy coupled with physiological and psychological changes, such risk factor pose a higher risk among the already vulnerable population.

Pregnancy and the postpartum period is an important period where the mother is generally provided with extra support by family members particularly, Tanzania is no exception. Lack of social support has been associated with increased risk of PPD in many studies conducted in different countries; Canada, Pakistan, China, Uganda $[22-25,41,42]$. The finding in our study is consistent with above studies where we found those women who were not satisfied with the family support they received, were at higher risk of PPD as compared to those who were satisfied with the family support they received during pregnancy and the postpartum period. These studies show that family support plays an important role in preventing PPD.

Evidence from this study should be interpreted carefully owing to the following three limitations. First, this was a cross-sectional study, therefore, we could not ascertain causality. However, our findings strongly correlate with those of other contexts. Second, Recall bias could also occur in this study, the disease state, preeclampsia or eclampsia, may add in the effect of recalling and therefore reducing confidence in answers to items asked. We tried to minimize this bias by providing quiet and ample time during the interview. Third, we conducted this study in a tertiary hospital and therefore, results may not be generalizable. Nevertheless, such results are consistent with other studies and may be useful in areas with similar context. Despite such limitations, this is the first study in our settings. So the results can be useful for planning and integrating PPD prevention and care package to women at risk.

\section{Conclusion}

One in every five women with a history of pre-eclampsia or eclampsia had features suggestive of PPD in Dar es Salaam, Tanzania. The magnitude of PPD increases with the severity of the disease condition. Women who were young, single with a lower level of education or having perinatal death had a higher risk of postpartum depression. Addressing PPD in this and similar context, it is important to tailor interventions and target younger women, those with a lower level of education, having perinatal deaths or stressful events, as well as those with the challenging supporting system. Postpartum depression screening should be an integral part of postnatal care especially among women who had pre-eclampsia or eclampsia. Furthermore, Clinicians in maternal health should be aware of symptoms suggestive of PPD and be able to provide immediate care.

\section{Acknowledgements}

We convey our heartfelt gratitude to the participants, field staff (nurse midwives). We are also thankful to MNH for granting permission to conduct this study and to the Directorate of Postgraduate studies and office of Deputy Vice Chancellor for giving consent to publish this study.

\section{Authors' contributions}

BM, CK, SK conceptualized the study, BM collected, entered, and analyzed the data, and prepared the first manuscript. CK was involved in preparing and editing the manuscript. SK provided technical assistance in mental health issues and was involved in manuscript preparation. BS was involved in data analysis, preparation of the manuscript, and editing it. All co-authors read and approved the final manuscript.

\section{Funding}

This study was sponsored by the Ministry of Health and Social Welfare of the Tanzanian government through Master of Medicine degree in Obstetrics and Gynaecology program.

\section{Availability of data and materials}

The dataset used during and/or analyzed during the current study is not publicly available because it is still being used for other analyses in a research group. However, the dataset will be available from the corresponding author on reasonable request.

\section{Ethics approval and consent to participate}

The current study was approved by the Research and Ethics committee of the Muhimbili University of Health and Allied Sciences. Data collection followed all ethical guidelines and written informed consent was obtained prior to data collection.

Consent for publication

Not applicable.

\section{Competing interests}

The authors declare that they have no competing interests.

\section{Author details}

${ }^{1}$ Department of Obstetrics and Gynaecology, Muhimbili University of Health and Allied Sciences, 9 United Nations Road, 65001, Dar es Salaam, Tanzania. ${ }^{2}$ Department of Psychiatry and Mental Health, Muhimbili University of Health and Allied Sciences, 9 United Nations Road, 65001, Dar es Salaam, Tanzania. ${ }^{3}$ Department of Psychiatry and Mental Health, Muhimbili National Hospital, 65000, Dar es Salaam, Tanzania. ${ }^{4}$ School of Public Health and Social Sciences, Muhimbili University of Health and Allied Sciences, 9 United Nations Road, 65015, Dar es Salaam, Tanzania.

Received: 8 December 2017 Accepted: 2 July 2019

Published online: 29 July 2019

\section{References}

1. Michael W. O'hara, Annette M. Swain. Rates and risk of postpartum depression - a meta-analysis. International Review of Psychiatry. 2009;8(1): 37-54.

2. Fisher J, De MC, Patel V, Rahman A, Tran T, Holmes W. Prevalence and determinants of common perinatal mental disorders in women in low- and lower-middle-income countries : a systematic review. Bull World Heal Organ. 2012:90:139-49.

3. Adama ND, Foumane P, Pierre J, Olen K, Dohbit JS, Ngo E, et al. Prevalence and risk factors of postpartum depression in Yaounde, Cameroon. Open J Obstet Gynaecol. 2015;5:608-17.

4. Adewuya AO, Eegunranti AB, Lawal AM. Prevalence of postnatal depression in Western Nigerian women : a controlled study. Int J Psychiatry Clin Pract. 2005;9(1):60-4.

5. Khalifa DS, Glavin K, Bjertness E, Lien L. Postnatal depression among Sudanese women : prevalence and validation of the Edinburgh postnatal depression scale at 3 months postpartum. Int J Womens Health. 2015;7: 677-84.

6. Leahy-Warren P, McCauley G. Postnatal depression: prevalence, mother's perspectives and treatment. Arch Psychiatr Nurs. 2007;21(2):91-100. 
7. Field T. Postpartum depression effects on early interactions, parenting, and safety practices: a review. Infant Behav Dev. 2010;33(1):1-9.

8. Stein A, Pearson RM, Goodman SH, Rapa E, Rahman A, Mccallum M, et al. Effects of perinatal mental disorders on the fetus and child. Lancet. 2014; 384(9956):1800-19.

9. Ibanez G, Bernard JY, Rondet C, Peyre H, Forhan A, Kaminski M, et al. Effects of antenatal maternal depression and anxiety on children ' $s$ early cognitive development : a prospective cohort study. PLoS One. 2015;10(8):1-16.

10. Kingston D, Mcdonald S, Austin M, Tough S. Association between prenatal and postnatal psychological distress and toddler cognitive development : a systematic review. PLoS One. 2015;10(5). https://doi.org/10.1371/journal.pone.0126929.

11. Koutra K, Chatzi L. Antenatal and postnatal maternal mental health as determinants of infant neurodevelopment at 18 months of age in a mother child cohort (Rhea study) in Crete. Greece Soc Psychiatry Psychiatr Epidemiol. 2013:48(8):1335-45.

12. Oates M. Postnatal affective disorders. Part 1: an introduction. Obstet Gynaecol. 2008;(10):145-50. https://doi.org/10.1576/toag.10.3.145.27416.

13. Beck C. Predictors of postpartum depression: an update. Nurs Res. 2001; 50(5):275-85.

14. Mohammad Kl, Gamble J, Head D, Creedy DK. Prevalence and factors associated with the development of antenatal and postnatal depression among Jordanian women. Midwifery. 2011;27(6):238-45.

15. Blom EA, Jansen PW, Verhulst FC, Hofman A, Raat H, Jaddoe WW, et al. Perinatal complications increase the risk of postpartum depression. The generation R study. BJOG. 2010;117:1390-8.

16. Brussé I, Duvekot J, Jongerling J, Steegers E. Impaired maternal cognitive functioning after pregnancies complicated by severe pre eclampsia: a pilot case control study. Acta Obs Gynecol Scand. 2008;87(4):408-12.

17. Karaghan R, Geranmaye M, Janani L, Hantooshzade S. Preeclampsia and depression: a case control in Tehran. Arch Gynecol Obs. 2012;286(1):249-53.

18. Hoedjes M, Berks D, Vogel I, Franx A, Bangma M, Darlington A, et al. Postpartum depression after mild and severe preeclampsia. J Women's Heal. 2011;20(10):1535-42.

19. Cox JL, Holden JM, Sagovsky R. Detection of postnatal depression. Development of the 10-item Edinburgh postnatal depression scale. Br J Psychiatry. 1987;150:782-6.

20. Figueira P, Corrêa H, Malloy-Diniz L, Romano-Silva MA. Edinburgh postnatal depression scale for screening in the public health system. Rev Saude Publica. 2009;43(SUPPL. 1):79-84.

21. Bener A, Burgut FT, Ghuloum S, Sheikh J. A study of postpartum depression in a fast developing country : prevalence and related factors. Int J Psychiatry Med. 2012:43(4):325-37.

22. Dennis $C$, Janssen $P$, Singer J. Identifying women at-risk for postpartum depression in the immediate postpartum period. Acta Psychiatr Scand. 2004;110(5):338-46.

23. Kazmi SF, Khan M, Tahir R, Dil S, Khan AM. Relationship between social support and postpartum depression. Ann Pak Inst Med Sci. 2013;9(4):191-4.

24. Leung SSK, Martinson IM. Postpartum depression and related psychosocial variables in Hong Kong Chinese women : findings from a prospective study. Res Nurs Health. 2005;28:27-38

25. Kakyo TA, Muliira JK, Mbalinda SN, Kizza IB, Muliira RS. Factors associated with depressive symptoms among postpartum mothers in a rural district in Uganda. Midwifery. 2012;28(3):374-9.

26. Sword W, Landy CK, Thabane L, Watt S, Krueger P, Farine D, et al. Is mode of delivery associated with postpartum depression at 6 weeks : a prospective cohort study. BJOG An Int J Obstet Gynaecol. 2011;118:966-77.

27. Rich-edwards JW, Kleinman K, Abrams A, Harlow BL, Mclaughlin TJ, Joffe $H$, et al. Sociodemographic predictors of antenatal and postpartum depressive symptoms among women in a medical group practice. J Epidemiol Community Health. 2006;60(3):221-7.

28. Kheirabadi G-R, Maracy M-R, Barekatain M, Salehi M, Sadri G-H, Kelishadi M, et al. Risk factors of postpartum depression in rural areas of Isfahan Province. Iran Arch Iran Med. 2009;12(5):461-7.

29. Tannous L, Gigante LP, Fuchs SC, Busnello EDA. Postnatal depression in southern Brazil : prevalence and its demographic and socioeconomic determinants. BMC Psychiatry. 2008:8(1):1-8

30. Jeha D, Usta I, Ghulmiyyah L, Nassar A. A review of the risks and consequences of adolescent pregnancy. J Neonatal Perinatal Med. 2015;8:1-8.

31. Adewuya AO, Fatoye F, Ola BA, ljaodola O, Ibigbami S-M. Sociodemographic and obstetric risk factors for postpartum depressive symptoms in Nigerian women. J Psychiatr Pract. 2005;11(5):353-8.
32. Weobong B, Ha A, Soremekun S, Danso S, Owusu-agyei S, Prince M, et al. Determinants of postnatal depression in rural Ghana : findings from the Don population based cohort study. Depress Anxiety. 2015;32:108-19.

33. Anuradha $\mathrm{G}$, Sebanti $\mathrm{G}$. Evaluation of post partum depression in a tertiary hospital. J Obstet Gynaecol India. 2011;61(5):528-30.

34. Alfayumi-Zeadna S, Kaufman-Shriqui V, Zeadna A, Lauden A, Shoham-Vardi I. The association between sociodemographic characteristics and postpartum depression symptoms among Arab-Bedouin women in southern Israel. Depress Anxiety. 2015;32(2015):120-8.

35. Shivalli S, Gururaj N. Postnatal depression among rural women in South India : do socio-demographic, obstetric and pregnancy outcome have a role to play ? PLoS One. 2015;10(4):1-11.

36. Keyes katherine M, Charissa PB, Koenen KC, Shear MK. Psychiatric disorders across the life course in a national study. Am J Psychiatry. 2015;171(8):864-71.

37. Sutan R, Amin RM, Ariffin KB. Psychosocial impact of mothers with perinatal loss and its contributing factors : an insight. J Zhejiang Univ Sci B. 2010; 11(3):209-17.

38. Gausia K, Moran AC, Ali M, Ryder D, Fisher C, Koblinsky M. Psychological and social consequences among mothers suffering from perinatal loss : perspective from a low income country. BMC Public Health. 2011;11:451.

39. Stone SL, Diop H, Declercq E, Cabral HJ, Fox MP, Wise LA. Stressful events during pregnancy and postpartum depressive symptoms. J Women's Heal. 2015;24(5):384-93.

40. Nielsen DF, Videbech P, Hedegaard M, Dalby JS, Secher J. Postpartum depression : identification of women at risk. Br J Obstet Gynaecol. 2000;107: 1210-7.

41. Chojenta C, Hons BAP, Loxton D, Lucke J. How do previous mental health, social support, and stressful life events contribute to postnatal depression in a representative sample of Australian women? J Midwifery Womens Heal. 2012;57(2):145-50.

42. Vigod SN, Villegas $L$, Dennis C. Prevalence and risk factors for postpartum depression among women with preterm and low-birth-weight infants : a systematic review. BJOG. 2010;117:540-50.

\section{Publisher's Note}

Springer Nature remains neutral with regard to jurisdictional claims in published maps and institutional affiliations.

Ready to submit your research? Choose BMC and benefit from:

- fast, convenient online submission

- thorough peer review by experienced researchers in your field

- rapid publication on acceptance

- support for research data, including large and complex data types

- gold Open Access which fosters wider collaboration and increased citations

- maximum visibility for your research: over $100 \mathrm{M}$ website views per year

At $\mathrm{BMC}$, research is always in progress.

Learn more biomedcentral.com/submission 